\section{A rare case of recurrent urinary tract infection due to Trichosporon species in an immune-competent diabetic female patient}

\author{
Saroj Adhikari ${ }^{1}$, Bhuvan Saud ${ }^{2 *}$, Govinda Paudel ${ }^{2}$ and Sunita \\ Wagle $^{3}$ \\ ${ }^{1}$ Medical Laboratory Technologist, Nepal \\ ${ }^{2}$ Department of Medical Laboratory Technology, Janamaitri Foundation Institute of Health \\ Sciences (JFIHS), Hattiban, Lalitpur, Nepal \\ ${ }^{3}$ Nardevi Ayurveda Hospital, Kathmandu, Nepal
}

\section{Abstract}

Trichosporonosis is a disease caused by Trichosporon spp. which are ubiquitous anamorphic yeast that commonly inhabit the soil. In human they are found in the skin, gastrointestinal tract and respiratory tract. Globally, Trichosporon spp. infection is rare and remains scantily reported in urinary tract infections and disseminated invasive infection amongst immunocompromised and cancer patients with neutropenia. Trichosporon asahii is the most commonly reported species. Virulence factors like proteinases, lipases, and phospholipases may be responsible for disease manifestation. We report a case of recurrent urinary tract infection due to Trichosporon spp. in a 62-year-old immunocompetent diabetic female which remained misdiagnosed for a long period of time. The patient was subsequently treated successfully by oral fluconazole drug.

\section{More Information}

*Address for Correspondence: Bhuvan Saud, Department of Medical Laboratory Technology, Janamaitri Foundation Institute of Health Sciences (JFIHS), Hattiban, Lalitpur, Nepal, GPO Box 8322; Email: link2bhuvan@gmail.com

\section{Submitted: 31 August 2019 \\ Approved: 23 September 2019 \\ Published: 24 September 2019}

How to cite this article: Adhikari S, Saud B, Paudel G, Wagle S. A rare case of recurrent urinary tract infection due to Trichosporon species in an immune-competent diabetic female patient. Arch Case Rep. 2019; 3: 026-028.

DOI: dx.doi.org/10.29328/journal.acr.1001017

Copyright: () 2019 Adhikari S, et al. This is an open access article distributed under the Creative Commons Attribution License, which permits unrestricted use, distribution, and reproduction in any medium, provided the original work is properly cited

Keywords: Trichosporonosis; Diabetic; Urinary Tract infection; Nepal

Check for updates

\section{Introduction}

Trichosporon spp. are basidiomycetous yeast-like anamorphic organisms mainly found in soil and other environmental sources of tropical and temperate areas. In humans, these are rarely found in gastrointestinal tract, oral cavity, respiratory tract and skin surfaces [1]. The burden of Trichosporon spp. infection mainly represent the second or third most common non-Candida yeast infections causing invasive disease in patients with cancer [2]. Their pathogenicity is due to the presence of different virulence factors like production of enzymes (Proteases and phospholipases), presence of glucuronoxylomannan in cell wall (that protects from phagocytic activity) and biofilm formation (that protects from antifungal drugs and host immune responses) [1].

Trichosporon asahii (T. asahii) infection is found in different clinical conditions like nongranulocytopenia [3], nosocomial urinary tract infection [4], liver-kidney transplantation [5], acute myeloid leukemia [6], diabetes [7], as well as both immunocompromised [8] and immunocompetent [9], individuals of different age groups and gender. From the past
10-15 years, Trichosporon asahii has become an emerging pathogen mainly in cancer patients. However, Trichosporon spp. may also cause life-threatening sepsis in non-cancer patients and in disseminated infection it shows variety of clinical features like septic shock, pneumonia, renal failure, chorio-retinitis, and cutaneous lesions [10].

\section{Clinical Case}

A 62 year old woman visited hospital with the complaint of burning micturition and pain in the lower abdomen. She had received symptomatic treatment for urinary tract infection with antibacterial drugs several times in the recent past but the problem still persisted. She had the history of diabetes and hypertension. The blood pressure was under control (systolic pressure $-135 \mathrm{mmHg}$ and diastolic pressure $-90 \mathrm{mmHg}$ ). Her blood parameters were as follows: serum urea $=42 \mathrm{mg} / \mathrm{dl}$, serum creatinine $=0.9 \mathrm{mg} / \mathrm{dl}$, fasting glucose $=162 \mathrm{mg} / \mathrm{dl}$ and post prandial glucose $=230 \mathrm{mg} / \mathrm{dl}$, hemoglobin $=13.4 \mathrm{~g} / \mathrm{dl}$, total leukocyte count $=9,100 / \mu \mathrm{l}$. Urine microscopy revealed moderate number of pus cells and few budding yeast cells under high power field (40X objective). The patient's urine 
sample was sent for routine culture and sensitivity testing. The sample was inoculated with a standard loop on cysteine lactose electrolyte deficient (CLED) agar media (Hi-media, India) and incubated at $37^{\circ} \mathrm{C}$ overnight. The next day growth of pure colonies was observed. The colonies were $2-3 \mathrm{~mm}$ in diameter, creamy, dry with wrinkled margins, raised with depressed centers and having colony forming unit $>10^{5}$ per milliliter (CFU/mL) (Figure 1). Gram stain was performed (Figure 2) which revealed budding yeasts and hyphae which were septate having arthospores. Repeat urine sample was inoculated on Sabouraud's dextrose agar (Hi-media, India) slants at $28^{\circ} \mathrm{C}$ and $37^{\circ} \mathrm{C}$. Pure growth of yeast-like fungi was observed at both temperatures. Urease test was performed and the fungus was found to hydrolyze urea. Further tests for confirmation of spp. was not possible in the setting. Antifungal therapy with oral fluconazole was given to the patient, and urine sample for culture after treatment was found to be negative for the fungus after one week of treatment.

\section{Discussion}

Trichosporon spp. are widely distributed in nature, and are the emerging etiological agents of disseminated Trichosporonosis. Seven species including T. asahii, T. asteroides, T. cutaneum, T. inkin, T. mucoides, T. ovoides and T. loubieri are pathogenic to

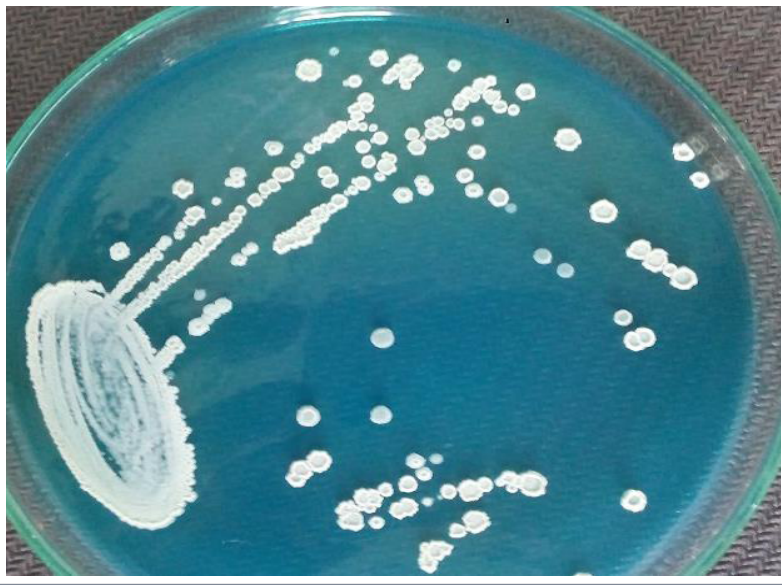

Figure 1: Dry, cream white colonies on CLED agar medium after overnight incubation.

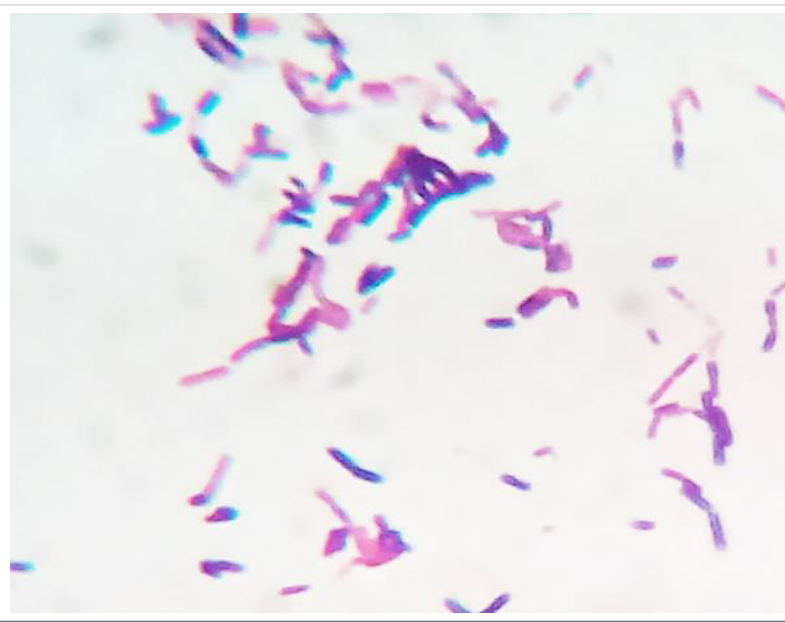

Figure 2: Gram's stained smear of the isolate as observed under 100X objective. human[11]. $T$ asahii is also well known to be responsible for causing white piedra and onychomycosis in immunocompetent patients [10]. Silvestre, et al. found that Trichosporon spp. colonized in $11.1 \%$ (112 out of 1,004$)$ of male healthy volunteers on their normal perigenital skin [12]. Treviño, et al. in their report have isolated T. asahii from 32 hospitalized patients in 2 years of study [13]. Mattede, et al. conducted a study on intensive care unit admitted patients in Brazil and found high prevalence rate i.e. $65 \%$ and mortality rate i.e. $20 \%$ [14] of $T$. asahii infection. Mortality rate has been found high in cancer patients which accounts to $80 \%$ among patients receiving amphotericin B therapy for treatment [15]. Early diagnosis and treatment of this kind of infection with appropriate antifungal agents may reduce the mortality rate. In the present case, the patient showed good response to fluconazole therapy. Other studies have also shown similar findings in invasive pulmonary infection [16], invasive Urinary Tract Infection (UTI) and nosocomial UTI caused by T. asahii [17]. However, another study also showed that diabetic patients with disseminated Trichosporonosis did not respond to fluconazole therapy and showed remarkable recovery after combination therapy of fluconazole and amphotericin B [18]. Recently, Premamalini, et al. reported that Trichosporon loubieri on rare occasion causes disseminated Trichosporonosis with high mortality rate and also causes UTI [19].

Although confirmatory tests for species identification could not be done, based on colony morphology, microscopic evidences for the presence septate hyphae and arthospore and urea hydrolysis test the pathogen was most likely Trichosporon asahii. To our knowledge, this is the first reported case of Trichosporon spp. from Nepal acting as an etiological agent of UTI in immunocompetent patients. The presence of moderate number of pus cells in both urine samples of the symptomatic female suggested active infection. Trichosporon spp. was isolated in both urine specimens from the patient and at the same time no bacterial isolate was evidenced. The patient was successfully treated with fluconazole therapy. Based on these evidences Trichosporon spp. was established as an etiological agent of UTI.

\section{Conclusion}

Most of the pathology laboratories in Nepal lack adequate diagnostic tools. Also, knowledge about fungal infections like with Trichosporon spp. is limited due to which they remain undiagnosed. Instead, based on sign and symptom and presence of pyuria patients receive treatment for bacterial infection without laboratory confirmation. Hence, in order to decrease the morbidity and to provide early diagnosis and quality treatment there is an urgent need to increase awareness amongst both laboratorians and clinicians in Nepal about fungaemia and fungal UTI. All laboratory staffs need adequate training on basic fungal culture and identification techniques and the facility for fungal culture should be made available at all microbiology laboratories. All samples for culture from immunocompromised patients should also be sent for fungal culture. 


\section{References}

1. Colombo AL, Padovan AC, Chaves GM. Current knowledge of Trichosporon spp. and Trichosporonosis. Clinical microbiology reviews. 2011; 24: 682-700.

PubMed: https://www.ncbi.nlm.nih.gov/pubmed/21976604

2. Pagano L, Caira $M$, Candoni $A$, Offidani $M$, Fianchi $L$, et al. The epidemiology of fungal infections in patients with hematologic malignancies: the SEIFEM-2004 study. Haematologica. 2006; 91: 10681075.

PubMed: https://www.ncbi.nlm.nih.gov/pubmed/16885047

3. Wolf DG, Falk R, Hacham M, Theelen B, Boekhout T, et al. Multidrug resistant Trichosporon asahii infection of nongranulocytopenic patients in three intensive care units. J Clin Microbiol. 2001; 39: 44204425.

PubMed: https://www.ncbi.nlm.nih.gov/pmc/articles/PMC88559/

4. Kumar S, Bandyopadhyay M, Mondal S, Pal N. A rare case of nosocomial urinary tract infection due to Trichosporon asahii. J Glob Infect Dis. 2011; 3: 319-310.

PubMed: https://www.ncbi.nlm.nih.gov/pmc/articles/PMC3162825/

5. Sah R, Soin AS, Chawla S, Wadhwa T, Gupta N. Disseminated Trichosporon asahii infection in a combined liver-kidney transplant recipient successfully treated with voriconazole. Immun Inflamm Dis. 2019; 7: 125-129.

PubMed: https://www.ncbi.nlm.nih.gov/pubmed/31006179

6. Cardenas-de la Garza JA, Ancer-Arellano J, Cuellar-Barboza A, et al Disseminated Trichosporon asahii infection in a patient with acute myeloid leukemia. J Dermatol. 2019; 46: e128-129.

PubMed: https://www.ncbi.nlm.nih.gov/pubmed/30295013

7. Iken M, Belkouch A, Bellarj B, Naoui $H$, Boumhil L, et al. A rare case of urinary tract infection due to Trichosporonasahii in a diabetic patient. Pan Afr Med J. 2015; 20: 127.

PubMed: https://www.ncbi.nlm.nih.gov/pubmed/26097631

8. Roman $A D$, Salvaña EM, Guzman-Peñamora MA, Roxas EA, Leyritana $\mathrm{KT}$, et al. Invasive Trichosporonosis in an AIDS patient: case report and review of the literature. Int J STD AIDS. 2014; 25: 70-75.

PubMed: https://www.ncbi.nlm.nih.gov/pubmed/23970618

9. Khan ID, Sahni AK, Basu A, Haleem S. Trichosporon asahii urinary tract infection in immunocompetent patients. Med J Armed Forces India. 2015; 71: 373-376.

PubMed: https://www.ncbi.nlm.nih.gov/pubmed/26663967
10. Ebright JR, Fairfax MR, Vazquez JA. Trichosporon asahii, a non-Candida yeast that caused fatal septic shock in a patient without cancer or neutropenia. Clin Infect Dis. 2001; 33: e28-30.

PubMed: https://www.ncbi.nlm.nih.gov/pubmed/11477533

11. Ahmad S, Al-Mahmeed M, Khan ZU. Characterization of Trichosporon species isolated from clinical specimens in Kuwait. J Med Microbiol. 2005; 54: 639-646.

PubMed: https://www.ncbi.nlm.nih.gov/pubmed/15947428

12. Silvestre Junior AM, Miranda MA, Camargo ZP. Trichosporon species isolated from the perigenital region, urine and catheters of a Brazilian population. Braz J Microbiol. 2010; 41: 628-634.

PubMed: https://www.ncbi.nlm.nih.gov/pmc/articles/PMC3768649/

13. Treviño $M$, García-Riestra $C$, Areses $P$, García $X$, Navarro $D$, et al. Emerging Trichosporon asahii in elderly patients: epidemiological and molecular analysis by the DiversiLab system. Eur $\mathrm{J}$ Clin Microbiol Infect Dis. 2014; 33: 1497-503.

PubMed: https://www.ncbi.nlm.nih.gov/pubmed/24718613

14. Mattede MD, Piras C, Mattede KD, Ferrari AT, Baldotto LS, et al. Urinary tract infections due to Trichosporon spp. in severely ill patients in an intensive care unit. Rev Bras Ter Intensiva. 2015; 27: 247-251. PubMed: https://www.ncbi.nlm.nih.gov/pmc/articles/PMC4592119/

15. Thibeault R, Champagne M, de Repentigny L, Fournet JC, Tapiero B, et al. Fatal disseminated Trichosporon asahii infection in a child with acute lymphoblasticleukemia.CanJInfectDisMedMicrobiol.2008;19:203-205. PubMed: https://www.ncbi.nlm.nih.gov/pubmed/19352453

16. Tsai MJ, Chang WA, Tsai KB, Chen HC, Hwang JJ, et al. Probable invasive pulmonary Trichosporonosis in a diabetic patient. Am J Respir Crit Care Med. 2011; 184: 982-982.

PubMed: https://www.ncbi.nlm.nih.gov/pubmed/22003150

17. Kucukates $\mathrm{E}$, Balkan I, Hondur N. A rare case of urinary tract infection due to Trichosporonasahii. J Pak Med Assoc. 2013; 63: 1041-1043.

18. Negi V, Sharma M, Juyal D, Kotian S, Sharma N. Disseminated Trichosporonosis due to Trichosporon asahii in a diabetic patient. Indian J Pathol Microbiol. 2015; 58: 246-248.

PubMed: https://www.ncbi.nlm.nih.gov/pubmed/25885147

19. Premamalini T, Anitha S, Rajyoganandh SV, Veena $H$, Kindo AJ. Complicated urinary tract infection by Trichosporon loubieri. Med Mycol Case Rep. 2019; 24: 86-89.

PubMed: https://www.ncbi.nlm.nih.gov/pubmed/31080715 